\title{
Letters
}

\section{Medical staff need to be aware of major incident planning}

EDITOR-Last month the BMA warned that too few people in the United Kingdom know how to respond to a terrorist attack. Its concerns about too few senior officials being aware of plans and recommendations to improve preparedness are sensible, but we believe that not enough medical staff are aware of their role in the event of a terrorist attack.

We recently carried out a survey in the largest acute NHS trust of the south west of England to assess medical staff's knowledge about the local major incident plan. We sent questionnaires to the 107 doctors in North Bristol NHS Trust with a potential role in the mobile medical team if they were on duty during a major incident.

Seventy seven doctors replied (72\%). Sixty nine were aware of the existence of the local major incident plan, but only 26 had read part or all of it. Only 11 of the responding doctors were aware of their potential role in the mobile medical team. Of these 11 doctors, only three thought themselves adequately trained for this position, and all three had been trained as medical incident officers.

Last year's National Audit Office report highlighted deficiencies in NHS plans to deal with major incidents in England. ${ }^{2}$ It recommended upgrading training arrangements. Five months later some doctors are still unaware of their roles in the event of a terrorist attack. As a trust we are currently considering several measures to improve on our results. We suspect, however, that our findings are not unique and encourage other acute trusts to look closely at their staff's knowledge and training and act accordingly.

Anusha G Edwards research registrar dr_ag_edwards@yahoo.com

Olly Donaldson preregistration house officer, department of paediatrics

Ed Walsh consultant anaesthetist

Southmead Hospital, Bristol BS10 5NB

Alexia Karantana surgical senior house officer Department of Orthopaedics, Frenchay Hospital, Bristol BS16 1JE

\section{bmj.com}

Letters appearing here are an edited selection of rapid responses originally posted on bmi.com

We ask for all letters to the editor to be submitted as rapid responses via bmj.com

For advice see: bmj.com/rapidresponses
Competing interests: None declared.

1 Kmietowicz Z. BMA warns that too few people know response to a terrorist attack. BMJ 2003;326:516. (8 March.)

2 National Audit Office. Facing the challenge: NHS emergency planning in England. London: NAO, 2002. Available at: planning in England. London: NAO, 2002. Avail 020336.pdf (accessed 26 Mar 2003).

\section{Contraindications to use of metformin}

Age and creatinine clearance need to be taken into consideration

EDITOR-Jones et al criticise current guidelines highlighting possible contraindications to the use of metformin as too vague and potentially leading to underuse in patients with type 2 diabetes. ${ }^{1}$ Although their desire for a "less ambiguous" approach seems sensible, their own guidelines still lack clarity.

They note that any specific value of serum creatinine concentration chosen as a cut-off point for prescribing metformin will be arbitrary because of variations in muscle mass and protein turnover. Despite this they then select-for undefined reasons - a serum creatinine value of $150 \mu \mathrm{mol} / \mathrm{l}$ as the cut-off point in their guideline. They then say that caution should therefore be used in prescribing metformin for elderly patients.

This is a vague statement, which could be interpreted as meaning that metformin should not be prescribed at all for elderly people, that specialist opinion should be sought or creatinine clearance calculated before it is prescribed, or that renal function or serum lactate concentration should be monitored after it is prescribed. ${ }^{2}$ In addition, the authors do not define elderly.

Given that the growing majority of patients with type 2 diabetes are over 65 and that there is already evidence of undertreatment in such patients, ${ }^{3}$ it seems particularly desirable to be as clear as is possible about this age group if the full benefits of treatment are to be attained.

Although the simple formulas that can be used to estimate creatinine clearance are not completely reliable, ${ }^{4}$ it may be preferable for prescription to be related to such a calculated estimate of clearance, which takes into account a patient's age, rather than the serum creatinine value alone.

Andrew T Elder consultant physician Western General Hospital, Edinburgh EH4 2XU andrew.elder@luht.scot.nhs.uk
Competing interests: None declared.

Jones GC, Macklin JP, Alexander WD. Contraindications to the use of metformin. BMJ 2003;326:4-5. (4 January.)

2 Chehade JM, Mooradian AD. Drug therapy: current and emerging agents. In: Sinclair AJ, Finucane P, eds. Diabetes in old age. Chichester: Wiley, 2001:202-3.

3 Hendra TJ, Sinclair AJ. Improving the care of elderly diabetic patients; the final report of the St Vincent Joint Task Force for Diabetes. Age Ageing 1997;26:3-6.

4 Cockcroft DW, Gault MH. Prediction of creatinine clearance from serum creatinine. Nephron 1976;16:31.

\section{Metformin may be useful in gestational} diabetes

EDITOR-The editorial by Jones et al on contraindications to the use of metformin did not mention pregnancy. ${ }^{1}$ Insulin is usually recommended in women with pregestational type 2 diabetes or gestational diabetes who require drug treatment. Given that pregnancy is a state of insulin resistance, metformin might be a logical alternative.

Cohort data support use of metformin in pregnancy. ${ }^{2}$ In a report about women with polycystic ovary syndrome who conceived while taking metformin, continuation of treatment through pregnancy reduced the incidence of gestational diabetes. ${ }^{3}$ One retrospective study has reported an increased rate of pre-eclampsia in pregnant women treated with metformin, but it is weakened by the lack of matched controls. The perinatal losses reported in the metformin group cannot be attributed to metformin treatment.

We recently completed a pilot study in 30 women with gestational diabetes diagnosed by the criteria of the Australasian Diabetes in Pregnancy Society (ADIPS). The women were randomised to metformin or insulin treatment. They were matched for age, parity, body mass index, and gestation at entry (table). The study had ethics approval, and the women gave written informed consent.

The outcome measure of fetal $\beta$ cell activity, assessed by cord C-peptide concentration, was not different in the two groups $(\mathrm{P}=0.31$; Mann-Whitney test; cord blood was stored from 17 women). Perinatal outcomes were not different (table), but numbers are too small to comment further. ${ }^{5}$

A larger trial has been started (the metformin in gestational diabetes (MiG) study). It has adequate power to test the hypothesis that metformin treatment compared with insulin in gestational diabetes will have similar perinatal outcomes, improve insulin sensitivity in both mother and baby, and be associated with improved treatment acceptability. Ethics approval has been obtained, and recruitment has started. A follow up study of the offspring will inves- 
Baseline characteristics and outcome data in women with gestational diabetes receiving insulin or metformin. Values are means (SD) unless stated otherwise

\begin{tabular}{|c|c|c|}
\hline Characteristic & Insulin ( $\mathrm{n}=14)$ & Metformin $(n=16)$ \\
\hline Maternal age (years) & $34.1(3.70)$ & $33.7(4.44)$ \\
\hline Median parity (range) & $1(0-5)$ & $1(0-4)$ \\
\hline Maternal weight at trial entry $(\mathrm{kg})$ & $101.2(22.01)$ & $104.4(22.28)$ \\
\hline Maternal body mass index at trial entry & $37.9(6.87)$ & $39.5(6.94)$ \\
\hline Gestation at diagnosis of gestational diabetes (weeks) & $27.6(3.80)$ & $25.8(5.51)$ \\
\hline \multicolumn{3}{|l|}{ Blood glucose (glucose tolerance test) (mmol/l) } \\
\hline Fasting & $5.4(0.52)$ & $5.6(1.26)$ \\
\hline $2 \mathrm{~h}$ & $9.4(1.42)$ & $10.0(2.07)$ \\
\hline Gestation at entry into trial (weeks) & $30.4(4.67)$ & $29.8(4.49)$ \\
\hline No (\%) with vaginal delivery & $11(79)$ & $5(31)$ \\
\hline No (\%) with induction of labour & $9(64)$ & $5(31)$ \\
\hline No (\%) with elective caesarean section & $2(14)$ & $8(50)$ \\
\hline No (\%) with emergency caesarean section & $1(7)$ & $2(13)$ \\
\hline No (\%) with pre-eclampsia & $2(14)$ & $3(19)$ \\
\hline Gestation at delivery (weeks) & $38.2(1.0)$ & $37.8(1.5)$ \\
\hline Birth weight $(\mathrm{g})$ & $3450(510)$ & $3560(50)$ \\
\hline No with birth weight $>4000 \mathrm{~g}$ & 2 & 2 \\
\hline Median cord C-peptide (range) (No) (pmol/ml) & $0.66(0.45-1.71)(7)$ & $0.53(0.35-2.86)(10)$ \\
\hline Cord glucose (mmol/l) (No) & $4.2(1.1)(11)$ & $4.2(1.9)(14)$ \\
\hline Cord glucose/C-peptide & $5.7(2.67)$ & $7.4(1.69)$ \\
\hline No of neonates with intravenous dextrose & 1 & 4 \\
\hline Median time in special care nursery (range) (h) & $24(0-102)$ & $48(0-360)$ \\
\hline No of neonates with jaundice & 6 & 3 \\
\hline No of neonates receiving phototherapy & 0 & 2 \\
\hline
\end{tabular}

tigate potential effects of metformin in relation to later insulin sensitivity and subsequent health. ${ }^{5}$

W M Hague consultant physician in obstetric medicine Department of Obstetrics, University of Adelaide, Queen Elizabeth Hospital, Woodville, SA 5011, Australia bill.hague@adelaide.edu.au

P M Davoren consultant physician

Department of Medicine, Gold Coast Hospital, University of Queensland, Southport, QLD 4215 Australia

Peter_Davoren@health.qld.gov.au

J Oliver associate professor

Department of Physiology, School of Medicine,

Flinders University, Bedford Park, SA 5042

Australia

johnno.oliver@flinders.edu.au

J Rowan consultant physician in obstetric medicine

National Women's Hospital, Auckland,

New Zealand

jrowan@internet.co.nz

Competing interests: None declared.

1 Jones GC, Macklin JP, Alexander WD. Contraindications to the use of metformin. BMJ 2003;326:4-5. (4 January.)

2 Coetzee E, Jackson W. The management of non-insulindependent diabetes during pregnancy. Diab Res Clin Pract 1986;1:281-7.

3 Glueck CJ, Wang P, Kobayashi S, Phillips H, Sieve-Smith L. Metformin therapy throughout pregnancy reduces the development of gestational diabetes in women with polycystic ovary syndrome. Fertil Steril 2002;77:520-5.

4 Hellmuth E, Damm P, Molsted-Pedersen L. Oral hypoglycaemic agents in 118 diabetic pregnancies. Diab Med 2000;17:507-11.

5 Barker D. Mothers, babies and health in later life. Edinburgh Churchill Livingstone, 1998.

Blanket banning of metformin two days before surgery may not be a good idea

EDITOR-The editorial by Jones et al makes several recommendations about improving the prescription of metformin. ${ }^{1}$ It is a pity that they advised stopping metformin two days before general anaesthesia when there is no evidence to suggest that this is warranted or even safe.
We conducted a Medline search using the keywords "metformin," "an(a)esthesia," "an(a)esthetics," "pre-operative," and "diabetes." We found no evidence supporting the unreferenced statement in their editorial

Jones et al point out that tissue hypoxia is commonly the trigger for metformin associated lactic acidosis and that metformin has a short half life except in advanced renal failure. It follows that it is illogical to suspend metformin earlier than the evening before most surgery unless a degree of tissue hypoxia already exists.

Avoiding metformin in patients with established or expected tissue hypoxia, or when substantial impairment of hepatorenal function perioperatively may be anticipated, is perfectly sensible. May we suggest the recommendations reflect this? Emergency surgery, cardiac surgery, operations requiring deliberate hypotension, and major vascular surgery would be examples where this modified advice would apply.

Much elective surgery, however, does not fit this description, and the recommendation by Jones et al will, necessarily, only be applicable to patients undergoing elective surgery. A blanket recommendation to stop metformin two days before going to theatre is not necessary, safe, or practical.

Philip Jones specialist registrar in anaesthetics psjones@doctors.org.uk

Paul Yate consultant anaesthetist

Barts and the London NHS Trust, London E1 1BB

Competing interests: None declared.

1 Jones GC, Macklin JP, Alexander WD. Contraindications to the use of metformin. BMJ 2003;326:4-5. (4 January.)

\section{Authors' reply}

EDITOR-Our aim was to maximise the use of metformin in patients, in whom it would improve cardiovascular risk, using a pragmatic set of guidelines. Although the United Kingdom prospective diabetes study does not include patients aged over $65,{ }^{1}$ we did not intend to prohibit metformin use in this age group.

Metformin does not affect lactate concentrations or turnover in elderly patients and, unlike insulin or sulphonylureas, does not cause hypoglycaemia, which can be problematic in older patients. Although, as we stated, a creatinine cut-off point of 150 $\mu \mathrm{mol} / \mathrm{l}$ is arbitrary, it is in keeping with guidelines from the Scottish Intercollegiate Group Network and the National Institute for Clinical Excellence for timing of referral for specialist opinion of type 2 diabetic patients with renal disease. ${ }^{34}$ Any cut-off point based on a calculated creatinine clearance would be equally arbitrary.

Although there are good theoretical reasons why metformin may be useful in gestational diabetes and pregnant type 2 diabetic patients, its safety is yet to be established. The pilot data of Hague et al show an increase in caesarean births, neonatal hypoglycaemia, and need for special care nursery in the metformin group. It will be interesting to see if these trends persist in an adequately powered study.

We agree with Jones and Yates that evidence on the safety of metformin around the time of surgery is lacking. Their recommendations are helpful. Contrast media containing iodine rarely cause renal failure ${ }^{5}$ - and, in a similar way, it may be overcautious to withdraw metformin after exposure to contrast media. None the less, prescribers could be open to criticism if they do not stop metformin treatment when there is even a risk of tissue hypoxia.

G C Jones consultant physician greg.jones@northglasgow.scot.nhs.uk

J P Macklin senior house officer

Department of Diabetes, Gartnavel General Hospital, Glasgow G12 0YN

W D Alexander consultant physician

Diabetes Centre, Western General Hospital, Edinburgh EH4 2XU

Competing interests: None declared.

1 UKPDS Study Group. Effect of Intensive blood glucose control with metformin on complications in overweight control with type 2 dibes (UKPDS 43). Lag patients with type

2 Lalau JD, Vermesh A, Hary L, Andrajek M, Isnard F, Quichaud J. Type 2 diabetes in the elderly: an assessment of metformin use in type 2 diabetes. Int Clin Pharmacol Ther Toxicol 1990;28:329-32

Scottish Intercollegiate Guidelines Network. SIGN 55 : Management of diabetes. A national clinical guideline. Edinburgh: Scottish Intercollegiate sicians, 2001

4 National Institute for Clinical Excellence. Management of type 2 diabetes-renal disease, prevention and early management. type 2 diabetes-renal disease, prevention and early management. London: NICE, 2002. WW

5 Deray G, Bellin MF, Boulchfar H, Baumelou B, Koskas F, Deray G, Bellin MF, Boulchfar H, Baumelou B, Koskas Baumelou $\mathrm{A}$, et al. Nephrotoxicity of contrast media in high risk patients whth renal insufticiency. comparison of 10w- and high-osmolar contrast agents. Am J Nephrol

\section{Increase in resources should lead to reduced waiting times}

EDITOR-Although highly topical, the paper by Martin et al on NHS waiting lists 
illustrates the misleading policy signals that can emerge from an inadequate analytic method. ${ }^{1}$ The paper finds little and inconsistent support for associations of prolonged waiting times with markers of capacity, independent sector activity, or need in the surgical specialties examined. Hard pressed policy makers might therefore infer that increased resources will not ameliorate the problem of NHS waiting times.

Yet an emerging economic literature, to which the authors do not refer, indicates the reverse. The key problem is that the waiting phenomenon may be the result of a subtle interaction between the demand for and supply of surgical capacity. Consequently, contemporary associations between capacity and waiting time will reflect a jumble of influences on demand and supply. A model is required that enables analysts to disentangle the effects of demand and supply.

Applying these principles to two years' data from the English hospital episode statistics database, we found that supply is indeed influenced by waiting times. ${ }^{2}$ Our findings have since been replicated on a longer time series of data and for separate services. ${ }^{3}$ They are also supported by a time series analysis of waiting list $\mathrm{KH} 07$ data. ${ }^{4}$ The implication of this work is that a permanent increase in NHS resources will contribute to a reduction in waiting times, other things being equal.

Martin et al outline some of the limitations of their study, and we, too, acknowledge that our work has its own shortcomings. However, simple cross sectional associations between waiting time and various other factors are far too flimsy a basis from which to make policy inferences, particularly when there is clear evidence that the waiting phenomenon reflects both the pressures of demand and supply.

Stephen Martin research fellow, department of economics and related studies

sdm1@york.ac.uk

Peter C. Smith professor of economics, Centre for Health Economics

University of York, York YO10 5DD

Competing interests: Our work on waiting times has been funded by the Department of Health.

1 Martin RM, Sterne JAC, Gunnell D, Ebrahim S, Smith GD, Frankel S. NHS waiting lists and evidence of national or Frankel S. NHS waiting lists and evidence of national or local failure: analysis of he

2 Martin S, Smith P. Rationing by waiting lists: an empirical investigation.J Public Econ 1999;71:141-64. 3 investigation. J Public Econ 1999;71:141-64. times for NHS surgery.J Royal Stat Soc Series A (in press). Gravelle $\mathrm{H}$, Smith P, Xavier A. Performance signals in the public sector: the case
Papers 2003;55:81-103.

\section{New structures of governance are needed}

Editor-Klein sees the "cacophony of accountabilities" for new NHS foundation hospitals as a weakness, ${ }^{1}$ but I would argue that it may be their greatest strength.

For half a century, the NHS has been organised as an administrative bureaucracy led from Whitehall, and the many structural reforms of the past two decades have done nothing to change this. No other major public service is so centralised. This bureaucracy has struggled in recent years to absorb increased resources and to deliver improved performance, and the difficulties of running this $£ 70$ bn organisation by administrative diktat from Richmond House have become painfully apparent.

Foundation hospitals offer a vision of a new model of governance and accountability in the NHS, replacing a vertical hierarchy topped by the Department of Health with a network of more autonomous healthcare providers still working within the values, standards, and requirements of the NHS. Foundation hospitals will have a network of accountability relations with their local communities, local government, other NHS organisations, national regulators, and the Department of Health. Plurality will replace the department's current, unhealthy monopoly of control.

Although the government's guidance on the practical details of foundation hospitals still needs work, ${ }^{3}$ the principle seems to have been accepted across the political spectrum. It does not make political, financial, or organisational sense to try to run the NHS from the Department of Health in Whitehall, and new structures of governance are needed that will make NHS organisations more accountable to the communities they serve. Kieran M J Walshe director of research management
Manchester Centre for Healthcare Management, Manchester Centre for Healthcare Managemen,
University of Manchester, Manchester M13 9PL kieran.walshe@man.ac.uk

1 Klein R. Governance for NHS foundation trusts. $B M$ J 2003;326:174-5. (25 January.)

Walshe K. Foundation hospitals: a new direction for NHS Walshe K. Foundation hospitals: a
reform? J Royal Soc Med (in press).

3 Department of Health. A guide to NHS foundation trusts. London: Department of Health, 2002.

\section{Drug treatment of hypertension}

\section{Conclusion of editorial is somewhat} flawed

EDITOR-In his analysis of the major results of the recently published antihypertensive and lipid lowering treatment to prevent heart attack trial (ALLHAT), Williams concludes that the key message from this trial is that what matters most is getting blood pressure controlled and that this is overwhelmingly more important than the means. ${ }^{12}$

ALLHAT showed that all blood pressure drugs were not "created" equally. ${ }^{2}$ Williams correctly points out important differences in the secondary cause specific end points between chlorthalidone and its active comparators: doxazosin (increased congestive heart failure), lisinopril (increased stroke and coronary end points), and amlodipine (increased stroke). For this very reason, the data safety monitoring board of the ALLHAT trial recommended discontinuance of the doxazosin arm.

There are other characteristics of blood pressure drugs, other than their effect on so called hard end points, that are as important as getting blood pressure controlled. These include cost, profile of adverse effects, ease of use (once daily versus several daily doses), and interactions with other drug agents. In all aspects, thiazide type diuretics come up tops as first line agents. This was amply shown in the systolic hypertension in the elderly programme (SHEP) and Medical Research Council studies, in which thiazide diuretics were associated with a greater than $40 \%$ reduction in the risk of stroke in patients with isolated systolic hypertension; these studies were conducted and completed more than a decade ago. ${ }^{3}$ ALLHAT also showed the differences in tolerability between agents, and the particular difficulty in controlling blood pressure to target values especially with angiotensin converting enzyme inhibitors in black patients.

In choosing a therapeutic agent to lower blood pressure and reduce cardiovascular risk, one must look at not only the blood pressure lowering effect but also important clinical end points that we are aiming to prevent, as well as issues such as cost and tolerability.

Daniel G Hackam chief medical resident

Department of Medicine, Faculty of Health Sciences, McMaster University, Hamilton, Ontario, Canada L8L 2X2

danielhackam@hotmail.com

Competing interests: None declared.

\section{Williams B. Drug treatment of hypertension. $B M J$ 2003;326:61-2. (11 January.) \\ 2 ALLHAT Officers and Coordinators for the ALLHAT Collaborative Research Group. Major outcomes in high-risk hypertensive patients randomized to high-risk hypertensive patients randomized to angiotensin-converting enzyme inhibitor or calcium chan-

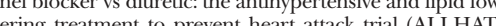 ering treatment to prevent heart attack trial (ALLHAT) \\ 3 SHEP Cooperative Research Group authors. Prevention of stroke by antihypertensive drug treatment in older per- sons with isolated systolic hypertension. Final results of the Systolic Hypertension in the Eldely Program (SHEP). JAMA 1991,265:3255-64. \\ MRC Working Party. Medical Research Council trial of treatment of hypertension in older adults: principal results.
$B M J$ 1992:304:405-12.}

\section{Thiazides with your pension?}

EDITOR-As Williams says in his editorial, the antihypertensive and lipid lowering treatment to prevent heart attack trial (ALLHAT) reaffirms the use of thiazide diuretics as a first line treatment for the older population with hypertension. ${ }^{1}$ But what about older patients who are not hypertensive?

For more than 20 years we have seen numerous studies that indicate that thiazide diuretics, in the usual antihypertensive doses, preserve bone mineralisation, ${ }^{2}$ and, importantly, the use of thiazide diuretics seems to be associated with a $30-40 \%$ reduction in the risk of hip fracture. ${ }^{34}$

However, if we are to start our thiazide at the same time we pick up our pension then we really need a randomised controlled trial. It is perverse that we do not have such a study because thiazides are so cheap. If modern health care is to maximise its potential, then healthcare agencies need to be prepared to pick up the costs for appropriate research and relicensing of older drugs, and not just the costs of the 
patented drugs from which pharmaceutical companies calculate they can make a profit.

John S Ashcroft general practitioner

Old Station Surgery, Ilkeston, Derbyshire DE7 8ES jsashcroft@doctors.org.uk

Competing interests: None declared.

Williams B. Drug treatment of hypertension. $B M$ 2003:326:61-2. (11 January)

2 Wasnich RD, Benfante RJ, Yano K, Heilbrun L, Vogel JM Thiazide effect on the mineral content of bone. $N$ Engl $J$ Med 1983;309;344-7.

3 Cauley JA, Cummings SR, Seeley DG, Black D, Browner W, Cauley JA, Cummings SR, Seeley DG, Black D, Browner W, Kuller LH, et al. Effects of thiazide diuretic therapy on bone mass, fractures, and falls. The Osteoporotic F

Researeh Group. Ann Intern Med 1993;118:666-73.

Feskanich D, Willett WC, Stampfer Mj, Colditz GA. A prospective study of thiazide use and fractures in women
Osteoporosis $\ln t$ 1997:7:79-84.

\section{Identifying malnourished children may not be easy}

EDIToR-Bahn et al propose to use the World Health Organization's criteria for diagnosing malnutrition, ${ }^{1}$ which include calculating $\mathrm{Z}$ scores for weight for height, and height for age.

Rural hospitals in resource poor areas are often severely understaffed but at the same time have high admission rates of especially small children. The amount of strain that measuring the heights of all admitted children puts on the medical and nursing staff should not be underestimated. Measuring is considered to be too time consuming and of little value in establishing the diagnosis and is therefore often left out in the assessment of the child.

In many hospitals in rural Kenya malnutrition is diagnosed only on clinical grounds such as weight, presence of pedal oedema, and discolouration of the hair. To try to measure the correlation between clinical diagnosis and more objective assessment through anthropometric indices, we conducted a study in Misikhu Mission Hospital in western Kenya. ${ }^{2}$ For five months all admitted children under the age of 5 years $(\mathrm{n}=1130)$, had their anthropometric indices calculated by using Epi-Info software and then compared with the clinical diagnosis.

Sixteen per cent of the admitted children were wasted (weight for height score $<2 \mathrm{SD}$ below the mean), and an additional 16\% were stunted (height for age score $<2$ SD below the mean). Just $14 \%$ of the wasted children and $11 \%$ of the stunted children were identified by clinical assessment as having malnutrition and would have got appropriate treatment when only clinical variables were taken into account at the time of diagnosis.

Measuring height cannot be left out when assessing the possible presence of malnutrition in a child. Once the diagnosis is made, the guidelines mentioned by Bahn et al should help the doctor in the actual treatment of malnourished children.

Frank van Leth clinical epidemiologist International Antiviral Therapy Evaluation Center Meibergdreef 9, NL-1105 AZ Amsterdam,

Netherlands

f.c.vanleth@amc.uva.nl

Competing interests: None declared.
1 Bhan MK, Bhandari, Bahl R. Management of the severely MK, Bhandari, Bahl R. Management of the severely malnourished child: perspective from developing coun-
tries. BMJ 2003;326:146-151. (18 January.) van Leth FCM, Koeleman JM, Manya AS. Malnutrition:
More than the eye can see. East Afr Med J 2000;77:549-51.

\section{Skin scarring: new insights may make adjustment easier}

EDITOR-Skin scarring is a clinical problem that can cause many psychological and social difficulties-some as a result of the cause of the scarring (for example, trauma), some related to the effects (for example, itching), and many to the appearance of the scar itself. In the review by Bayat et al their argument that a decision to treat will depend on site, symptoms, severity of functional impairment, and stigma would be enhanced by the inclusion of two crucial insights from recent psychological literature, insights that can make it much easier for patients to adjust to these problems.

Firstly, much research has now confirmed that the seriousness of psychosocial sequelae is not positively correlated with the severity, size, or location of scarring. ${ }^{2}$ It is therefore important in the clinical examination and assessment process that doctors do not make assumptions about the psychosocial impact of scarring-it is important to ask patients about how self conscious they feel, for example, and how noticeable they feel the scar is to others because these factors are likely to be more predictive of distress.

Secondly, recognising that even with the skills of surgeons and others, scars cannot yet be made to disappear has prompted new psychosocial interventions to be developed for patients distressed by disfigurements of any kind, including scarring, to their face, hands, and body. These have focused on the strengthening of self esteem and communication skills (so as to manage the reactions of other people) and are available in various formats including in self-help guides produced by a charity, Changing Faces (for example, Everybody's Staring at Me! How to Communicate When You Have an Unusual Face). These new interventions are becoming known to psychologists across the NHS and can be delivered by individual psychologists or through a centralised referral unit such as the outlook unit at Frenchay Hospital, Bristol. ${ }^{4}$

James Partridge chief executive

Changing Faces, London W2 1PN

jamesp@changingfaces.co.uk

Nichola Rumsey professor of appearance and health psychology

Centre for Appearance Research, University of the West of England, Bristol BS16 1QY

nichola.rumsey@uwe.ac.uk

1 Bayat A, McGrouther DA, Ferguson MWJ. Skin scarring. BMJ 2003;326:88-92. (11 January.)

BMJ 2003;326:88-92 Robinson E. Psychological research on visible differences in adults. In Lansdown R., Rumsey N, Bradbury E, Carr A, Partridge J, eds. Visibly different: coping with disfigurement.

3 Rumsey N, Clarke A, Musa M. Altered body image: the psychosocial needs of patients. Br J Community Nur

Kleve L, Rumsey N, Wyn-Williams M, White P. The effectiveness of cognitive-behavioural interventions provided at outlook-a disfigurement support unit. J Evalua Clin Pract 2002;8:387-95.

\section{"Author pays" as new science publishing model}

\section{Several models of scientific publishing are likely}

EDITOR-According to Delamothe, a consensus is emerging on how the internet will change the economics of scientific publishing. ${ }^{1}$ As far as I am aware no journal relying solely on charging authors for online publication has yet managed to derive sufficient revenue from this model to meet its running costs.

Our approach at Oxford University Press is to maximise the dissemination of our online journals by adapting the traditional subscription model to extend online access to groups of institutions, companies, whole states, or countries. We also offer free online access to the poorest developing countries, and we participate in archives such as those provided by PubMed Central and HighWire Press. In addition, we are experimenting with other pricing models, including charging authors for publication and providing "free" online versions subsidised from print revenues or by advertising.

I think that, although the virtual world is changing the economics of scientific publishing, in the real world no single model is likely to meet the needs of every author or reader. Open access journals funded by author charges may eventually prove to be the economic model of choice in some cases, but most journals, unless they also benefit from grants or subsidies, will need to rely on a mixture of economic models to continue to support the costs of online publication.

Martin Richardson journals director Oxford University Press, Oxford OX2 6DP richarm@oup.co.uk

Competing interests: MR is journals director at Oxford University Press, a department of the University of Oxford.

1 Delamothe T. "Author pays" may be the new science publishing model. BMJ 2003;326:182. (25 January.)

\section{Cautious welcome is in order}

EDITOR-I welcome the development outlined by Delamothe that authors should pay for publication of their work, while appreciating the difficulties many journals face in providing free access, as well as the authors' desire to publish and retain copyright of their work. ${ }^{1}$ However, my welcome is qualified.

Firstly, Delamothe talks of the hope that agencies funding the original research will agree to foot the authors' bill. What happens with authors who do not have such a luxury?

Secondly, what effect will the authors pay model have on research from developing countries reaching the wider audience it craves and deserves? Such research, of course, is already disadvantaged on many fronts.

Ahmad Risk editor

Health Informatics Europe, Brighton BN3 2JD

risk@cybermedic.org 
Competing interests: AR is a member of the editorial board of the Journal of Medical Internet Research, an author-pays journal and the official journal of the Internet Healthcare Coalition, of which AR is chair.

Delamothe T. "Author pays" may be the new science publishing model. BMJ 2003;326:182. (25 January.)

\section{It's time to wake up to the hidden agendas of free journals}

EDITOR-The concept of free online journals seems too good to be true. ${ }^{2}$ Certain hidden agendas need attention.

Firstly, journals are essentially asking the authors to ask their sponsors to pay for the cost of publication. Industries would grab such opportunities to publish their works. Journals might then be flooded with publications sponsored by industry. Such publications would convey the conclusions favourable to the industry, and positive results would be published more often than negative ones. ${ }^{3} \quad$ Researchers' growing dependence on the industry, accompanied by a decline in support from the government, makes this a distinct probability. ${ }^{3}$

Secondly, researchers who do not have major sponsors would miss out on publications in journals of their choice.

Thirdly, the fact that industry would pay for the cost of publication means two tier journals would be produced. The so called free journal might in effect be the proxy mouthpiece of the industry, which is exemplified by the existing notion that free journals are simply vehicles for advertisements. ${ }^{4}$

Fourthly, the "paid" journals would struggle to cater in the conventional way. Worse, if the authors have to reach into their pockets to pay (in the absence of sponsorship) £936 (\$1500, €1460) per article, it would be interesting to see how many papers would be published. In such an eventuality only the "quality" journals would be able to survive. Paradoxically, given the current non-competitive nature of journals, some may view this as a blessing in disguise. ${ }^{5}$

Debasish Debnath clinical research fellow

Department of Surgery, University of Aberdeen,

Aberdeen AB25 2ZD

d.debnath@abdn.ac.uk

Competing interests: None declared.

1 Delamothe T. "Authors pays" may be the new science publishing model. BMJ 2003;326:182. (25 January.)

Eaton L. Online medical publishing venture gets unde way. BMJ 2003;326:11. (4 January.)

way. BMJ 2003;326:11. (4 January.)
Hopkins J. Industry is deeply involved in funding US research. BMJ 2003;326:179.

Rennie D. The present state of medical journals. Lancet 1998;352(suppl 2):18-22

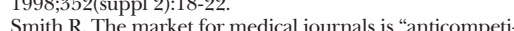

tive," says expert. BMJ 2003;326:182.

\section{"Free" medical publishing venture gets under way}

\section{Open access monopoly may threaten smaller journals}

EDITOR-I am editor and publisher of a small but (in my opinion) high quality open access journal (Journal of Medical Internet
Research (JMIR)) (www.jmir.org), which has been open access since its inception in 1999 and which recently introduced an article processing fee of $\$ 500$ (£306; €463). I therefore cannot help feeling threatened by a powerful organisation such as the Public Library of Science (PLoS), with a backing of $\$ 9 \mathrm{~m}$ and influential people at the top. ${ }^{1}$

I wonder why-if you have $\$ 9 \mathrm{~m}$-you still need to charge the authors three times more than we charge for an article, although we do not have any funding for the journal (except $\$ 500$ mini-grants from the Soros Foundation, for fee waivers for needy authors). On the other hand, it is good that the PLoS fee is so high-otherwise smaller open access journals such as ours that need to charge a fee would be in trouble. PLoS might accidentally destroy what it means to foster: open access journals.

I wish foundations and scientists (peer reviewing and writing for journals) supported groups of scientists taking publishing into their own hands by using the web, rather than supporting megalomaniac organisations that aim to centralise and dominate. Open access has been made possible through the internet, and the internet is a wonderful decentralised medium. Let's keep it that way. We are just trying to free ourselves from the oligarchy of large publishing houses. Why do we need to create a new mega-organisation that tries to monopolise publishing? Establishing an online journal, setting up a peer review system, and getting the journal indexed in bibliographic databases is not rocket science. The group of editors that runs JMIR has decided that it needs neither BioMed Central nor PLoS for that.

PLoS should stay what it was-an advocacy group-but not enter into a competition with existing open access journals. If PLoS wants to use the $\$ 9 \mathrm{~m}$ wisely, it should use it to support existing open access journals rather than competing with them.

Gunther Eysenbach associate professor University of Toronto, Toronto, Canada M5G 2C4 geysenba@uhnres.utoronto.ca

Competing interests: GE is the (unpaid) editor and publisher of an open access journal (www. jmir.org). This journal is independent from BioMed Central and PLoS-and it should stay that way. 1 Eaton L. Online medical publishing venture gets under
way. BMJ 2003;326:11. (4 January.)

\section{Publishing is getting expensive}

EDITOR-Wow-£936 (\$1530; €1415) to have your article published-that's expensive. ${ }^{1}$ It should cost a reasonably efficient organisation about $£ 100$ to peer review an article (www.carnall.org/peerrev.htm). Even if a subeditor takes another day or two to get the article in shape this wouldn't come to $£ 800$. For $£ 936$ you could buy a webserver and a couple of years of internet connection, and do it yourself.

Harold Varmus must be on a good salary. Or perhaps it is being priced to fail? Oh well. One way or another knowledge will out.
Douglas Carnall general practitioner

London E8 1AJ

dougie@carnall.org

Competing interests: DC runs a webserver to publish my own work and have a vision of a free, democratic future in which others do likewise.

1 Eaton L. Online medical publishing venture gets under way. BMJ 2003;326:11. (4 January.)

\section{Sore throats, why the dilemma?}

EDITOR-With reference to the article by Kumar et al, I find it hard to believe that the argument still goes on about the treatment of sore throats. ${ }^{1}$ If I had the energy I would dig up the articles to support the following statements

Firstly, the only probably treatable organism in the throat is streptococcus, virtually all else is viral.

Secondly, during the second world war the US government decided that the only sensible treatment was to give all troops complaining of a sore throat an injection of penicillin. They were unlikely to complete a 10 day course of antibiotics orally, and the risk of anaphylaxis was less than the risk of a war injury.

Thirdly, multiple studies show that it is very difficult to get anyone to complete a 10 day course of penicillin.

Fourthly, drug resistance is on the rise due to overuse of antibiotics.

Fifthly, rapid tests for streptococci have been available for over 10 years. They can give reliable results within minutes and have been standard practice in the United States for ages but very unpopular with UK authorities. Could it be because the penicillin is cheaper than the test?

Sixthly, there is only weak evidence that treating strep throat with antibiotics hastens resolution of symptoms, but we would like to believe that it will reduce the presence of secondary complications such as rheumatic fever and quinsy (but not glomerulonephritis)

If you are determined to reduce the overuse of antibiotics either do a culture and wait 24-48 hours to treat positive results or do a rapid strep test and treat patients whose results are positive. Either strategy will prevent complications and would be equally efficacious in relieving symptoms. In the developing world or inner cities, where only relatively ill patients come to the doctor and compliance is difficult, an injection of penicillin or short course of azithromycin is sensible. Once the patients realise that the complaint of sore throat is greeted with an injection they will be very judicious of their use of the doctor's services.

Larry Martel consultant paediatrician Warren Children's Centre, Lisburn, Northern Ireland BT28 1LQ martel@doctors.org.uk

Competing interests: None declared.

1 Kumar S, Little P, Britten N. Why do general practitioners prescribe antibiotics for sore throats? Grounded theor interview study. BMJ 2003;326:138-41. (18 January.) 